\title{
From the Archives
}

\section{Sociological Theory in Nigeria: What For?}

\section{Carolyne Dennis *}

DOI: $10.36108 / \mathrm{NJSA} / 0102 / 80(0150)$

Vol. 8 Issue 1, 2010

\begin{abstract}
The paper attempts to show that the sociological position of sociologists in Nigeria and their intellectual training is likely to give them a predisposition to accept a particular theoretical orientation. This is quantitative analysis based on Parsonian variables. It is argued that in the Nigerian context this approach has limitations which need to be recognised. An alternative theoretical orientation in terms of 'subjective understanding' and a 'critical sociology' is suggested and also the argument that if we are aware of the limitations of particular theories, we are more likely to be able to formulate an explanatory theory for Nigerian society. The argument is put forward that sociological theory in Europe and the United States developed in response to a situation of very rapid social change and that if one recognises the limitations on theories, developed in Europe, in the Nigerian context, perhaps the present situation of rapid social change in Nigeria will act as a similar stimulus to the development of sociological theory.
\end{abstract}

\section{Introduction}

One of the most self-interested reasons for teaching is that it acts as a superb heuristic device for one's own research. And one of the most self-interested reasons for teaching sociological theory is that it raises fundamental questions which are often possible to ignore in one's own research. It might, therefore, be instructive to discuss the problems raised by the explication and construction of sociological theory in Nigeria, not primarily in relation to its use in research but in relation to the way in which we teach sociological theory to our students. This is an area where basic assumptions are either more difficult to disguise or they are so much taken for granted that we feel no need to disguise them.

I would like to begin with a consideration of the position of intellectuals in economically underdeveloped societies, and then, more specifically with their position in Nigeria; to proceed from this to a discussion of the sociological traditions by which we are most influenced and finally, to suggest that there might be alternative orientations which sociologists should consider.

Since the mid-nineteenth century in Russia, intellectuals in developing countries have been identified as a social group who have articulated the need for change in society, change characterised by modernisation and rationalisation in the administrative and economic structure. ${ }^{1}$ In a society where there is a powerful landed interest and a patrimonial administration, the rationalisation of these spheres has serious implications for the existing political elite. It 
threatens ${ }^{*}$ their ruling position in society by proposing the creation of administrative and economic resources they cannot control. This challenge to existing political structures has, in the past, often led to a direct confrontation between the intellectuals and those who control the prevailing social order. In this situation, the intellectuals have had to turn to the peasants or workers as the other groups, at least potentially hostile to the status quo, in order to achieve their aims. $^{2}$

In Nigeria, at least in the South, the dominant group, both politically and economically, has been precisely those modernising intellectuals, entrepreneurs and lately bureaucrats. These groups possess the very qualifications regarded as essential for organising rational administration and technological advance. Questions concerning the way in which this modernisation is to be achieved are therefore likely to be perceived as administrative rather than political questions. ${ }^{3}$ This is very similar to the phenomenon known in America as the 'end of ideology'. ${ }^{4}$ The prevailing ideology is one of the necessities of modernisation. This contrasts strongly with the situation outlined above of the hostility of entrenched feudal elite to modernisation. It would appear that this is likely to have implications for the position of the intellectual vis-à-vis his society.

In Nigerian society, the educational system is regarded as the way to provide the skilled manpower, at various levels, on which modernisation depends. ${ }^{5}$ The function of the universities is to provide the highest level of trained manpower and the specific function of the social science faculties within the universities, is to provide the policy makers or their advisers, and administrators. In addition to this there is in Nigeria a specific combination of a lack of trained manpower, which gives a great value to those who are trained, and a relatively large number of universities which provides a career structure for 'intellectuals'. The intellectuals, therefore, are institutionalised into bureaucratically structured universities, founded under the influence of the AngloAmerican model. They are relatively well paid; they have security and a definite social function, in that they train high level manpower and engage in policy-orientated research. ${ }^{6}$ I think that it is evident that this differs somewhat from the 'ideal type' outlined above of the position of intellectuals in economically underdeveloped societies.

There are many schools of sociological research and I do not wish to suggest that one of them has the key to the truth. Nor do I wish to undertake some sort of content analysis of the lectures of my colleagues still less of my own lectures. But I do wish to suggest that by the very nature of the traditions of sociology within which we work, there is one theoretical approach which we are more likely to adopt than others. This approach, like all others, has

\footnotetext{
* Carolyne Dennis lecturered at the University of Ife, Ile-Ife, now Obafemi Awolowo University, in the seventies. This paper originally appeared in the first edition of the Nigerian Journal of Sociology and Anthropology in 1974.
} 
limitations of which we need to be aware, and perhaps try to change. The approach I wish to discuss is the quantitative methods based on the use of Parsonian variables.

The dominant theoretical orientation of sociologists in both American and British universities has, for a long time, been based on the theories of Talcott Parsons. He seeks to analyse particular societies in terms of very elaborate classificatory systems and polarities. When Parsonian analysis is specifically applied to economically underdeveloped societies, it uses as its basis the traditional-modern dichotomy expressed in the 'pattern variables'. ${ }^{7}$ This is of doubtful theoretical and empirical validity. ${ }^{8}$ The use of this dichotomy is based on the assumption that 'progress' is dependent upon how far traditional forms of social organisation and technology give way to more 'Advanced' forms of rationality and technology. These more advanced forms are assumed to be the highest achievement of Western industrial capitalism. The relationship between Western industrial capitalist societies with those of the underdeveloped world is perceived as that of diffusion and innovation, from the source of rationality and technology. Perhaps one may remark here that it is ironic that one of the most conservative in ideology of American sociologists and certainly one of the most able apologists for industrial capitalism should have been adopted by sociologists in Nigeria. ${ }^{9}$

Parsons himself uses the pattern variables to construct ideal polarities but a large body of research in American and British universities is based on the attempt to measure quantitatively the extent to which particularly societies are modern or potentially modern, using these variables. ${ }^{10}$ The use of these variables for quantitative measurement rests on the assumptions that they are value free and that they provide indicators of real social structure. They also imply that human behaviour is fundamentally predictable. If these assumptions are regarded as correct, this kind of research has particularly important implications for research concerned with policy formulation and evaluation. I would tentatively suggest that there is perhaps an 'elective affinity' between social scientists in Nigeria, given their institutionalisation and policy orientation in research, and teaching based on the quantification of Parsonian variables. ${ }^{11}$ This has implications for the way we teach sociology. Obviously one would not attempt to assert that there is a stereotyped method of teaching sociology in Nigeria but I do think that there is a coherent orientation closely related to the theoretical approach I have outlined above, which can be identified and discussed.

In our foundation courses we tend to use basic functionalist assumptions expressed in the concept, variously formulated, that there are functional prerequisites for the existence of society which are met by its various institutions. ${ }^{12}$ Most students are also given an historical introduction to the development of sociological theory by an explanation of the work of a few sociologists, usually reified as the 'Founding Fathers'. Many of the more 
advanced sociological courses which we teach are quite rightly concerned with the problem of social change; with giving a causal explanation of change or of examining its implications for particular social institutions, i.e., urbanization, population growth. In this area, the theoretical assumptions on the basis of which we construct our courses relies less heavily on functionalist assumptions, one assumes because this is the field in which functionalist explanations are least successful. Given the discussion above concerning the 'elective affinity' between sociologists in Nigerian and Parsonian theory, it is not surprising that it is in this area that the Parsonian variables are perceived as most relevant.

One of the characteristics of a fundamentally functionalist approach is that it provides an impressive classificatory system without necessarily raising critical questions concerning the ways in which particular societies are organised; they tend to be regarded as 'givens'. On top of this classification is provided the system of Parsonian variables which purports to explain the process of social change but in reality provides the study with a more precise and sophisticated classificatory scheme than that of the introductory functionalism. On the basis of this system, one then goes on to teach the students to measure how far particular societies correspond to the criteria of modernisation put forward. This approach is extended to methodology courses where the emphasis is on methods which will provide basic quantitative data and the provision of the kind of data which is seen as the prerequisite for policy orientated research. The 'Founding Fathers' and other approaches to sociological theory fit rather awkwardly within this framework of teaching sociology. The theory course becomes an isolated act of filial piety towards the origins of sociology, and therefore has little to offer either teachers or students in the examination of particular sociological problems.

It is understandable how this emphasis arises. In the Nigerian context, the problem of collecting quantitative data is a difficult one and such data is essential for the development of sociology. But it is not the whole of sociology. Sociology involves more than the collection of quantitative data, and a training in social research methods clearly involves more than a training in social survey methods. Where these methods are emphasized to the exclusion of others and we receive training and practice only in these methods, there are implications for the kind of research we carry out. The large scale survey involves the solution of many administrative problems both for the organisers and the individuals who are interviewing. Questions of administering the survey easily become more important than questions of the quality of the questionnaire and the underlying assumptions of the project. This may result in a tendency to regard the human beings under observation as objects of study rather than as subjects for understanding; it would be surprising if it were otherwise. One is, therefore, in danger of creating a situation in which students, who are an elite group in Nigerian society, and perhaps more importantly, regard themselves as elite, are given the kind of research orientation which asks them to perceive the behaviour of the other members of their society as 
the product of predictable, interacting variables. The attitude of the survey towards its subjects very easily becomes both administrative and manipulative. It does not lead to a meaningful interaction between the student and the people he is studying. This has significant and unfortunate implications for Nigerian society in the light of the fact that many of these students, by virtue of their training, will eventually be formulating policy for, or administering, the very people they are studying in this way.

A point concerning the relationship between sociological theory and method emerges, I hope, from the previous discussion which is significant for what follows. This is that the theoretical assumptions we make have important consequences for the social research methods we use. And if we refuse to make an explicit link between sociological theory and research methods, this does not lead to value free research methods but to a situation where our theoretical assumptions are taken for granted. I would suggest that the usefulness of 'taken for granted' theory is limited.

If we are to consider whether there is an alternative method of teaching sociological theory to our students, perhaps we really need to go back to first principles and ask why sociology students wish to study sociology; assuming that they are intelligent enough to know that there are not scores of very highly paid positions waiting for them. Students study sociology because they think that it may help them understand the world, especially a world which is changing rapidly and because they think that it might help them to formulate answers to specific problems, i.e., that of modernisation. I would submit that sociology is primarily concerned with understanding the world. ${ }^{13}$ The attempt to change the world to make policy for it is secondary, not because it is unimportant, but because it cannot be embarked upon with any degree of efficiency without an adequate understanding of society. We must also remember that it is not a self evident truth that being useful to society is of necessity the same as being useful to a particular government.

Sociological theories are constructed in an attempt to understand society. The development of sociology in the nineteenth century in Europe is explicable in terms of the disruption of the social order of Europe as a consequence of industrialization. ${ }^{14}$ It was therefore an attempt to do systematically what people in general and sociology students in particular wish to do--to make sense of their own society. But the nineteenth century sociologists were trying to understand industrial capitalist society. The history of sociological thought must examine the work of these theorists within this context. It is necessary to do this in order to analyse the relevance of these theories, or their nonrelevance for the post-colonial or neo-colonial or neo-colonial world. This world, which includes Nigeria, was transformed by the impact of industrial capitalism. It transformed the social structure and the whole system of values of these societies. But to try to understand post-colonial societies through the perspective of nineteenth century European or twentieth century American 
social theory is, as it were, to look at them down the wrong end of a telescope. If theories are studied in order to apply them to Nigerian society, there would be little point in studying theorists who were concerned to explain a very different kind of society. But they can be extremely useful if one studies them in order, by critical analysis, to determine what ought to be the elements of an adequate explanation of society which is the first step towards the construction of a theoretical explanation of one's own.

If the purpose of sociology is to understand the world, then we have to realise that there are more ways than one of perceiving a given phenomenon. What the sociologist needs to be able to do is to make explicit the assumptions, implications and limitations of particular frameworks of explanation. This should be the contribution of sociological theory to the training of sociologists.

Sociological theories cannot be used like boxes to encapsulate reality; their usefulness is tested by how far they enable us to understand that reality, to perceive what is the nature of that reality. This is not something that can be observed and measured. It requires the dimension of subjective understanding. ${ }^{14}$ Subjective understanding requires an inter-subjective interpretation of the meanings which actors attribute to the social world in which they find themselves. I would like to suggest, therefore, that it would be very useful for sociology students to be trained to sit and listen to how 'ordinary' people think and how they explain their social world. And it would be an invaluable experience for them to have to regard their 'poor' subjects' explanations of the world as coherent and intrinsically important. Apart from contributing to the students' ability to formulate a theoretical explanation and thereby understand society, this articulation and clarification of the way people explain their society might perhaps make an important contribution to the provision of humane policy recommendations. ${ }^{15}$

If one considers that this is the direction in which the teaching of sociological theory should go, it is because it is attempting to help create the kind of sociologists who are both flexible and capable of adapting to new situations and able to put themselves in the position of other people. Peter Berger expresses very well the kind of sociologist one is trying to produce and I think that one is well justified in quoting him at length:

We maintain that the teaching of sociology is justified insofar as a liberal education is assumed to have a more than etymological connection with intellectual liberation. Where this assumption does not exist, where education is understood in purely technical or professional terms, let sociology be eliminated from the curriculum. It will only interfere with the smooth operation of the latter, provided of course, that sociology has not also been emasculated in accordance with the educational ethos prevailing in such situations. Where however, the assumption still holds, sociology is justified by the belief that it is better to be conscious than unconscious and that consciousness is a condition of freedom. To attain a greater measure of awareness, and with it of freedom, entails a certain amount of suffering and even risk. An educational process that would 
avoid this becomes simple technical training and ceases to have any relationship to the civilising of the mind. We contend that it is part of a civilised mind in our age to have come in touch with the peculiarly modern, peculiarly timely form of critical thought that we call sociology. Even those who do not find in this intellectual pursuit their own particular demon, as Weber put it, will by this contact have become a little less stolid in their prejudices, a little more careful in their own commitments and a little more sceptical about the commitments of others and perhaps a little more compassionate in their journeys through society. ${ }^{16}$

This is not to suggest that one can produce sociology students who are capable of changing society in a particular direction. That is not the purpose of academic courses and it is more dependent upon structural factors in society than the ideological orientation of a small number of sociology graduates. It does however mean on the part of teacher and hopefully of students, a commitment to a 'critical' approach which does not identify government with society. The particular kind of field work outlined above might be helpful in this direction. If Berger is right in his evaluation of sociology and if, as was discussed above, many sociology students will, after graduation, be engaged in policy making or administration, these qualities of flexibility and the ability to understand others would, one imagines, make them more creative and constructive administrators and policy makers. If one teaches sociology in this way, one is forced to make one's assumptions explicit and to examine them. One also has to examine the assumptions and implications of existing theories of the explanation of social reality. There is no sociological theory specifically formulated to explain the social situation in which we find ourselves. One can therefore assume that the existing theories will be somewhat limited in their usefulness to an analysis of that situation.

In the 'Structure of Social Action', Talcott Parsons discusses how advances in the social sciences have taken place in situations where existing presuppositions proved inadequate to explain specific empirical problems and that consequently these presuppositions were questioned by such theorists as Marshall, Durkheim and Pareto. They transcended these presuppositions without necessarily being aware of the implications of doing so. Parsons' account of the way in which sociological theory advances corresponds very closely to the process of 'crisis' caused by the emergence of anomalous facts, by which Kuhn explains progress in the natural science. ${ }^{17}$ Perhaps then the very absence of an adequate explanatory framework in a situation of rapid social change, in which people feel the need to make sense of what is happening, may produce a significant advance in sociological theory. 


\section{Acknowledgement}

I would like to thank Gavin Williams for very constructive discussion during the preparation of this article.

\section{References}

1. Bendix, R. 'On Tradition and Modernity', Journal of Social Issues, (October 1968).

2. Catalyst, 1967, A. Frank "Underdevelopment and Revolution". See the lives of Lenin, Frantz Fanon and Amilcar Calbra, for example.

3. See the Second Nigerian National Development Plan.

4. See Bell, D. The End of Ideology, and C. Wright Mills" critique of the thesis in The Sociological Imagination.

5. See the Ashby Report (1959).

6. See the 'Quarterly Journal of Administration', University of Ife, Vol. V, No. 3, (April 1971), F. Okediji's article on 'The Social Implications of the Plan' for the argument that social scientists should be consulted more on policy decisions.

7. T. Parsons, The Social System.

8. See Jamil Hilal, The Sociology of Development, unpublished paper, Durham University (1969).

9. This is a subject to which one cannot do full justice here but the conservative aspect of Parsons' thought can be indicated by his functional approach to the problem of social stratification and his understanding of class conflict in terms of the tension between a stress on individual achievement and the imperatives of bureaucratic organisation. See C. Wright Mills, The Sociological Imagination, and Andrew Hacker 'Sociology and Ideology' in Max Black, The Sociological Theories of Talcott Parsons.

10. See American Political Science Review (1951) Karl Deutsch.

11. See Francis Olu Okediji 'Social and Educational Aspects of the Rehabilitation of Beggars', Paper given at a seminar/workshop on 'The Rehabilitation of Beggars Throughout the Federation of Nigeria' (12-13 May, 1973) Ibadan. Quarterly Journal of Administration, Vol. VII, No. 1 (October 1972), University of Ife, O.O. Soleye 'Compiling Strike Statistics in Nigeria' which centres on the need to compile strike statistics to, among other things, promote 'Industrial relations'. There is no indication that strikes may also be studied for their illumination of social structure and processes. See also Quarterly Journal of Administration, Vol. V, No. 2 (January 1971), A. A. Akiwowo 'Linkages between Social Science Research and Decision Makers in Nigeria which is a subtle approach to the problem but which states that one of the links could come from social scientists 'settling of generally acceptable national development objectives' which implies some degree of identification with the aims of a particular government. 
12. Kingsley Davis, Human Society is a very competent example of this approach.

13. See Max Weber, Theory of Social and Economic Organisation, Chapter 1. The insistence on 'subjective understanding' as a necessary starting point is not to deny the need for causal explanation in sociology. Weber concentrates on the need for the study of recurrent phenomena which have relevance for value - which are concerned with the attainment of values with which we are concerned. See Max Weber 'Methodology of the Social Sciences' p. 50. It is not however necessary to link the two. I, myself, would prefer a critical Marxist approach to the analysis of social structures and processes. What is at issue here is the usefulness of starting with the method of 'subjective understanding'.

14. An interesting step in this direction is that in Nigerian Opinion, Vol. 15, Nos. 8-10 (August-October 1969), Akinsola Akiwowo 'Observations on the Sociological Enterprise in Nigeria', but this approach is formulated mainly in terms of the linguistic contribution of everyday Yoruba life to sociological explanation.

15. See Nisbet, R. Social Change and History.

16. Peter Berger, Invitation to Sociology, p. 198.

17. Thomas Kuhn, The Structure of Scientific Revolutions. 